\title{
Biomimetic Synthesis of Silver Nanoparticles from Aqueous Extract of Saraca indica and its Profound Antibacterial Activity
}

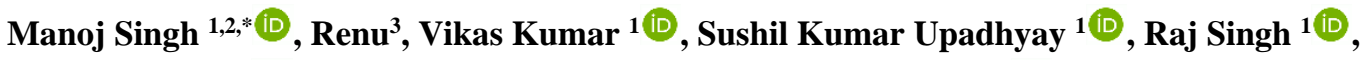 \\ Mukesh Yadav ${ }^{1}$ (D), Seema ${ }^{1}$, Sunil Kumari ${ }^{1}$, Anil Kumar Sharma ${ }^{1}$ (D), Subramanian Manikanadan ${ }^{4}$ \\ 1 Department of Biotechnology, Maharishi Markandeshwar (Deemed to be University), Mullana-Ambala (Haryana), India \\ 2 Laboratory of Biomedical Nanomaterials, National University of Science and Technology "MISiS", 119049, Moscow, \\ Leninsky Prospect, 4. Russia \\ 3 Department of Botany, S.D. (P.G.) College, Panipat -132103, Haryana, India \\ 4 Center for Environment \& Water, Research Institute, King Fahd University of Petroleum \& Minerals 31261, Dhahran, \\ Kingdom of Saudi Arabia \\ * Correspondence: lookformanoj@gmail.com;
}

Scopus Author ID 57214312802

Received: 24.06.2020; Revised: 14.07.2020; Accepted: 15.07.2020; Published: 18.07.2020

\begin{abstract}
The present findings were focused on green synthesis of silver nanoparticles through an aqueous extract of Saraca indica. The stability of the nanoparticle was achieved through the optimization of physico-chemical parameters. The sharp UV-visible absorption maximum at 400 was observed for biological synthesized silver nanoparticles. The spectroscopic analysis was thus used to assess the formation of silver nanoparticles. The AFM analysis did analyze the morphology of the nanocomposite, which was further confirmed through TEM micrograph. The electron micrograph image discloses that silver nanoparticles were polydispersed and dominantly as spherical with size ranges from $40 \mathrm{~nm}$ to $100 \mathrm{~nm}$. The average size distribution was $49 \mathrm{~nm}$. The chemical reductions of $\mathrm{Ag}+$ ions were further confirmed through FTIR. The biogenic silver nanoparticle and their drug formulation showed profound antibacterial activity against pathogenic bacteria. The flavonoids rich binding of silver nanoparticle showed great medicinal potential and can be used for the treatment of several harmful infectious diseases. Hence, plant-based metal nanoparticles meet the demand for less toxic formulation during drug development and its delivery.
\end{abstract}

Keywords: Antibacterial activity; Biogenic; Saraca indica; Atomic force microscopy; Electron micrograph.

(C) 2020 by the authors. This article is an open-access article distributed under the terms and conditions of the Creative Commons Attribution (CC BY) license (https://creativecommons.org/licenses/by/4.0/).

\section{Introduction}

Nanoparticles have been defined as the particles lesser than $100 \mathrm{~nm}$ in one dimension at atomic, molecular, and macromolecular scales [1]. An essential feature of nanoparticles is the high surface area to volume ratio [2]. There are some naturally occurring nanoparticles, and some have been designed, which are known as engineered nanoparticles. These engineered nanoparticles are generally used in the biomedical field as well as in the production of commercial products like sunscreen and cosmetics, etc. [3]. Nanoparticles have very functional platforms that can be utilized for imaging and therapeutic function [4]. There are mainly four types of nanoparticles based on the number of dimensions, including one-dimensional, twodimensional, three-dimensional, and zero-dimensional structures [5]. Nanoparticles can be 
synthesized by using different methods of synthesis, such as chemical reduction [6], electrochemical techniques [7], and photochemical reactions [8]. The natural compound or organisms, such as plant extract, fungi, and bacteria, act as reluctant and stabilizing agents, which could be considered as an alternative for the synthesis of inorganic nanoparticles [9]. The medicinal plants are a good source of biosynthesis of metal nanoparticles [10].

Silver in bulk form carries antimicrobial potential [11-12]. However, in a reduced state, the antimicrobial potential gets enhanced for silver nanoparticles [13]. The biological and chemical syntheses of silver nanoparticles have been widely studied for their therapeutic potential. [14-15]. The way in which the metal nanoparticle has gained interest, the various methods evolving in terms of less toxic chemical involvement, cost-effectiveness, and stability of nanoparticles are a prime area of interest [10]. The natural extracts contain active biomolecules which generally helps in reducing and binding of nanomaterials with specific receptors cell of the bacterial membrane [16]. These natural compounds may be rich in flavonoids, aldehydes, amides, polysaccharides, etc. [17]. The multidrug resistance of bacteria against bactericides and antibiotics is very common nowadays due to the development of resistant strains. Some natural compounds act as antimicrobial agents, and hence there is a need to develop novel ways of formulating biomaterials is an upcoming field of attraction [18]. In the present study, we focused on the biomimetic approach for the synthesis of silver nanoparticles. The physico-chemical optimization was done for controlled morphology (size and shape), and comparative antimicrobial potential of drugs formulated with nanoparticle against pathogenic bacteria was determined.

\section{Materials and Methods}

\subsection{Preparation of leave extract.}

For preparing, the aqueous extracellular solution of plant leaves, $5 \mathrm{~g}$ of freshly collected plant leaves of Saraca indica were cut chopped into appropriate size $(\sim 1 \mathrm{~cm} \times 1 \mathrm{~cm})$, and were taken to $250 \mathrm{ml}$ conical flask and washed several times with distilled water. After this, $100 \mathrm{ml}$ distilled water was added to the flask containing freshly chopped and washed plant leaves followed by the boiling at $60{ }^{\circ} \mathrm{C}$ for 15 minutes. The obtained crude extract was filtered through Whatman filter paper no.1, and the supernatant was stored at $4{ }^{\circ} \mathrm{C}$ and used within a week [10].

\subsection{Synthesis and physico-chemical optimization of silver nanoparticles.}

To obtain optimum conditions for maximum synthesis, the plant filtrate was used as a reducing and stabilizing agent for $1 \mathrm{mM} \mathrm{AgNO}_{3}$. In a typical optimization route, silver nanoparticles formed by the reduction of $\mathrm{Ag}^{+}$ions to $\mathrm{Ag}^{0}$. The process involved with the addition of $5 \mathrm{ml}$ filtrate to $30 \mathrm{ml}$ of $10^{-3} \mathrm{M} \mathrm{AgNO}_{3}$ solution in a $250 \mathrm{ml}$ flask and kept on a rotary shaker (120rpm) at $30{ }^{0} \mathrm{C}$ [19]. The nanoparticle synthesis was optimized by varying the different parameters [10]. The different parameters selected were mixing ratio $(1: 6,1: 7,1: 8$, and 1:9) and reaction temperature $\left(50^{\circ} \mathrm{C}, 60^{\circ} \mathrm{C}, 70^{\circ} \mathrm{C}\right.$, and $\left.80^{\circ} \mathrm{C}\right)$.

\subsection{Purification of silver nanoparticles.}

To remove the non-AgNPs components along with a maximal recovery of AgNPs colloids from the synthesized solution, an optimal centrifugation process was obtained based at $10,000 \mathrm{rpm}$ for $10 \mathrm{~min}$. The supernatant was collected and frozen at $-70{ }^{0} \mathrm{C}$ for $45 \mathrm{~min}$ for 2 
days using Lyophilizer (Micro Modulyo 230 freeze dryer, Thermo Electron Corporation, India). The lyophilized nanoparticles were stored desiccated at $4{ }^{0} \mathrm{C}$.

\subsection{Morphological characterization of silver nanoparticles.}

The absorbance pattern of silver nanoparticles was analyzed using a UV-visible spectrophotometer (UV-Vis), and the readings were recorded at a resolution of $1 \mathrm{~nm}$ between 300 and $700 \mathrm{~nm}$ in a $10 \mathrm{~mm}$ path length quartz cuvette. Atomic Force Microscopy (APE research: AI00SGS; USA) was analyzed to image the topography of soft biological materials in their native environments. The particle size analysis and distribution of the nanomaterial were analyzed by using a zeta sizer PALS (Phase Analysis Light Scattering) zeta potential analyzer ver. 3.54. The topographic information and surface chemistry of the sample was assessed through TEM. The Fourier Transformed Infrared (FTIR) spectroscopy was also analyzed to determine the chemical bond developed with silver nanoparticles. For all the analysis, samples were prepared according to the previously reported protocol [20].

\subsection{Microbial susceptibility test.}

Bacterial susceptibility to antibiotics formulated with biomimetic silver nanoparticles was studied against $E$. coli and $S$. aureus using a disk diffusion assay. To determine the combined effect of each standard drugs (ampicillin and ciprofloxacin), the paper disk was further impregnated with $20 \mu \mathrm{l}$ of the freshly prepared AgNPs. The agar plates and were left for an hour at $25{ }^{\circ} \mathrm{C}$ to allow diffusion in order to reduce the effects of variation in time between the applications of different solutions. The culture plates were incubated at $37{ }^{0} \mathrm{C}$ for 24 hours to determine the zone of inhibition. Three parallel tests were run with the standard for avoiding any errors.

\section{Results and Discussion}

\subsection{Biosynthesis of silver nanoparticles.}

The change of color from yellow to light brown was the confirmatory feature for silver nanoparticles formation due to the excitation of surface plasmon vibrations (Figure 1).

\subsection{UV-Vis spectroscopy.}

The light absorption pattern of the Saraca indica mediated synthesis of silver nanoparticles was kinetically monitored with the help of UV-Vis measurement at a different time interval (Figure 2). The spectra showed a well-defined surface plasmon band between $350-450 \mathrm{~nm}$ was the characteristic of silver nanoparticles and clearly indicated the formation of nanoparticles in solution [10]. The maximum absorbance occurred at 400nm and steadily increases in intensity as a function of reaction time. The nanoparticles solution was found to be extremely stable even after the month of the reaction. Our findings were also supported by Singh et al., (2012), who reported that polydispersed nanoparticles absorb the wavelength in the NIR region of the electromagnetic spectrum, which corresponds to the longitudinal surface plasmon absorption [21]. 

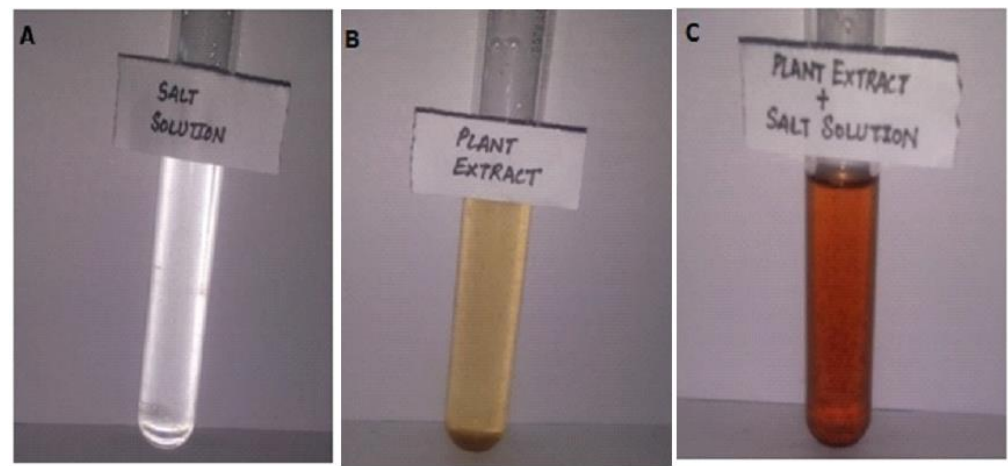

Figure 1. Transparent solution of silver nitrate (A), yellow color from aqueous leaf extract of Saraca indica (B), and light red-brown color indicating the formation of silver nanoparticles (C).

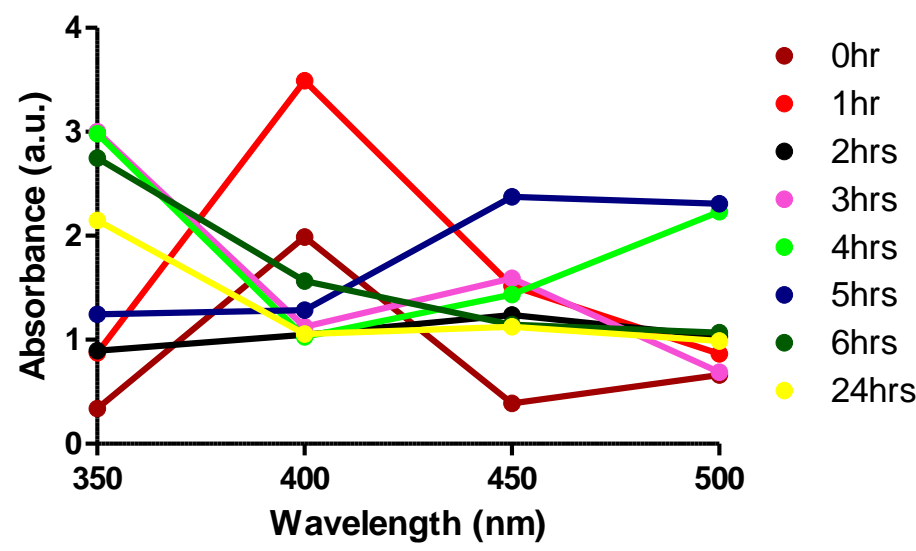

Figure 2. UV-Vis spectra recorded with respect to time after the reaction of $1 \mathrm{mM} \mathrm{AgNO}_{3}$ solution with $5 \%$ Saraca indica aqueous leaf extract for $24 \mathrm{~h}$.

\subsection{Atomic force microscopy (AFM).}

The obtained morphology revealed the fact that the synthesized silver nanoparticle was polydispersed and polyshaped. AFM images of the bio-functionalized organic layer rich in organic moieties at the surface confirmed the polydispersity of the nanoparticles. The particle size of the nanoparticle was around $49 \mathrm{~nm}$, respectively, as illustrated in Figure 3 [19].
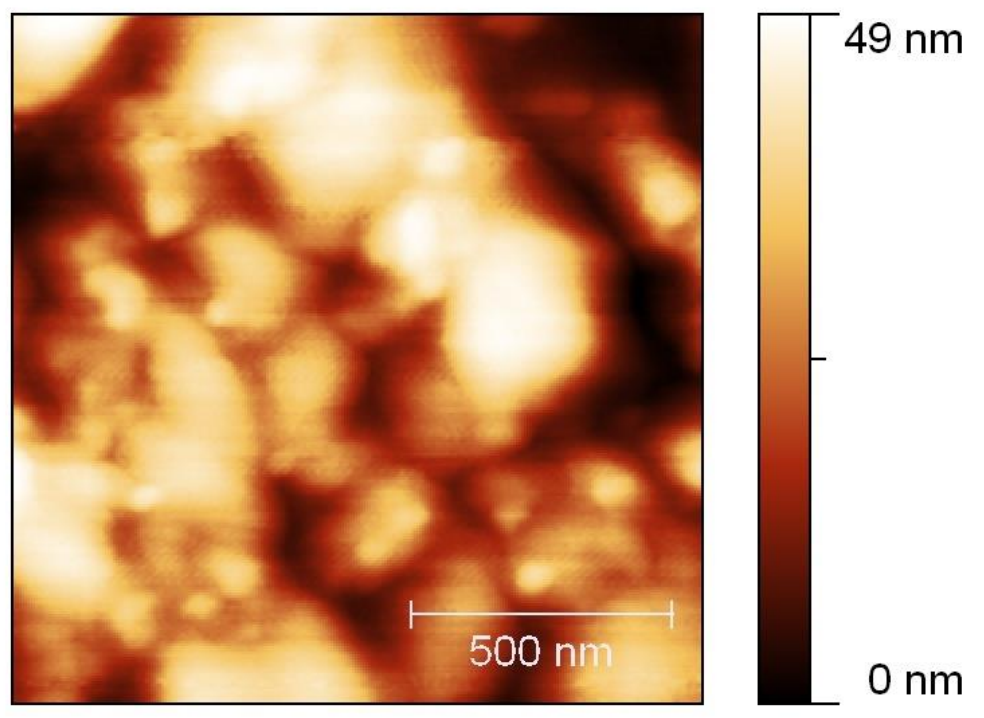

Figure 3. AFM image of silver nanoparticles synthesized by Saraca indica. 
3.4. Optimization of physico-chemical parameters.

The effects of different parameters were studied for AgNPs synthesized through aqueous leaf extract of Saraca indica at $400 \mathrm{~nm}$. The effect of different mixing ratio was studied in terms of intensity. The maximum absorbance was achieved with 1:8 mixing ratio. The initial absorption intensities at $350 \mathrm{~nm}$ for 1:6 concentrations were near to 2a.u. the different peaks for absorbance were monitored with an increase in time duration. The maximum absorbance was found to be 3.16a.u. after $6 \mathrm{hr}$ of synthesis(Figure 4 ). The maximum absorbance was found to be 3.76a.u after $3 \mathrm{hr}$ of synthesis for 1:7 mixing ratio (Figure 5). For 1:8 mixing ratio, the initial absorption intensities at $350 \mathrm{~nm}$ for silver nanoparticles were near to 1a.u. the different peaks for absorbance were monitored with an increase in time duration. The maximum absorbance was found to be 3.49a.u. after $1 \mathrm{hr}$ of synthesis (Figure 6). The maximum absorbance was found to be 3.72a.u. after $2 \mathrm{hr}$ of synthesis for 1:9 mixing ratio, respectively (Figure 7).

\section{$1: 6$ concentration}

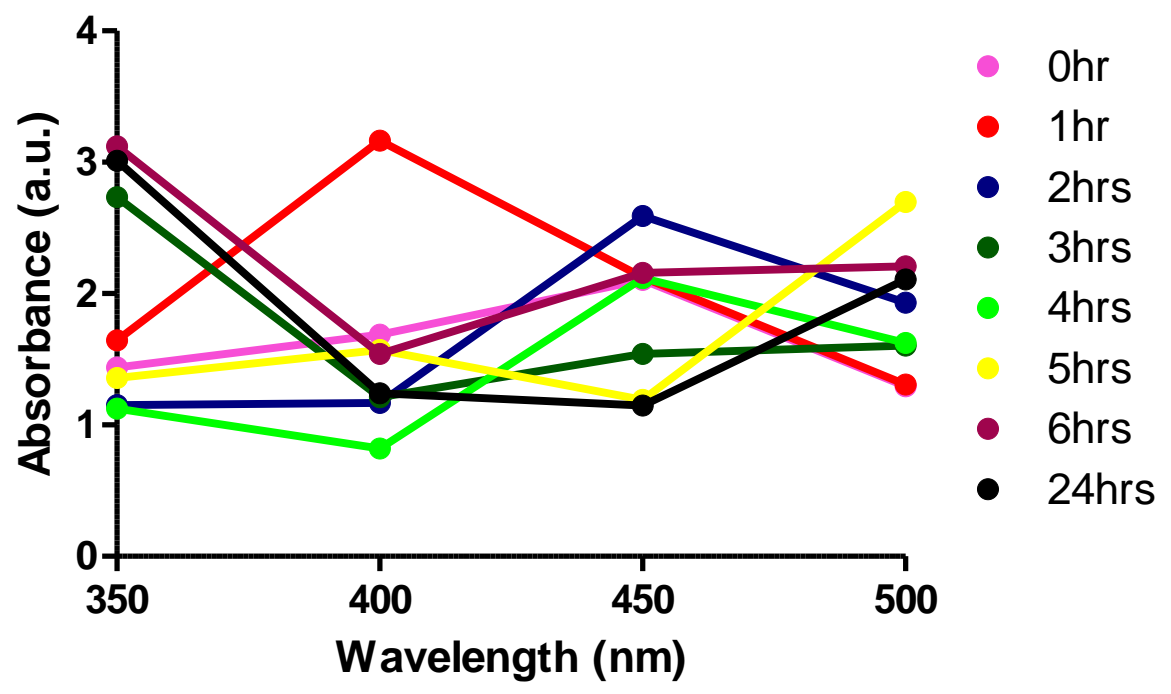

Figure 4. Effect of mixing ratio on the surface plasmon resonance of AgNPs with 1:6 mixing ratio.

\section{$1: 7$ concentration}

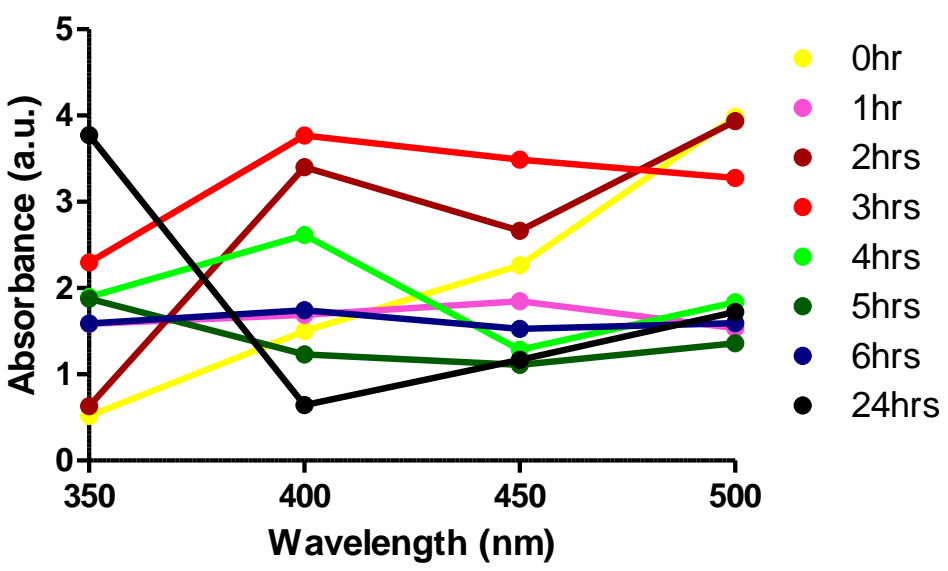

Figure 5. Effect of mixing ratio on the surface plasmon resonance of AgNPs with 1:7 mixing ratio. 


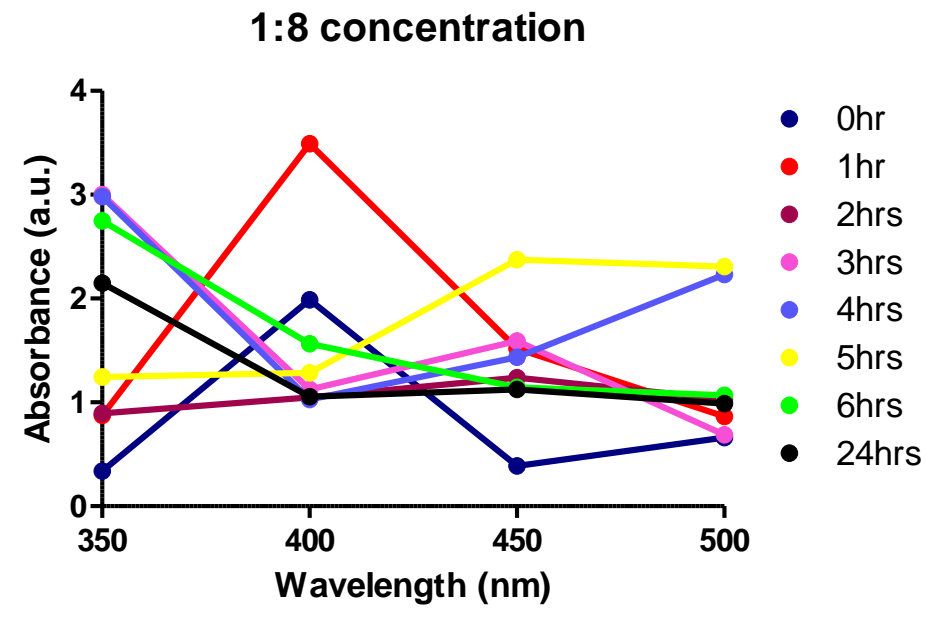

Figure 6. Effect of mixing ratio on the surface plasmon resonance of AgNPs with 1:8 mixing ratio.

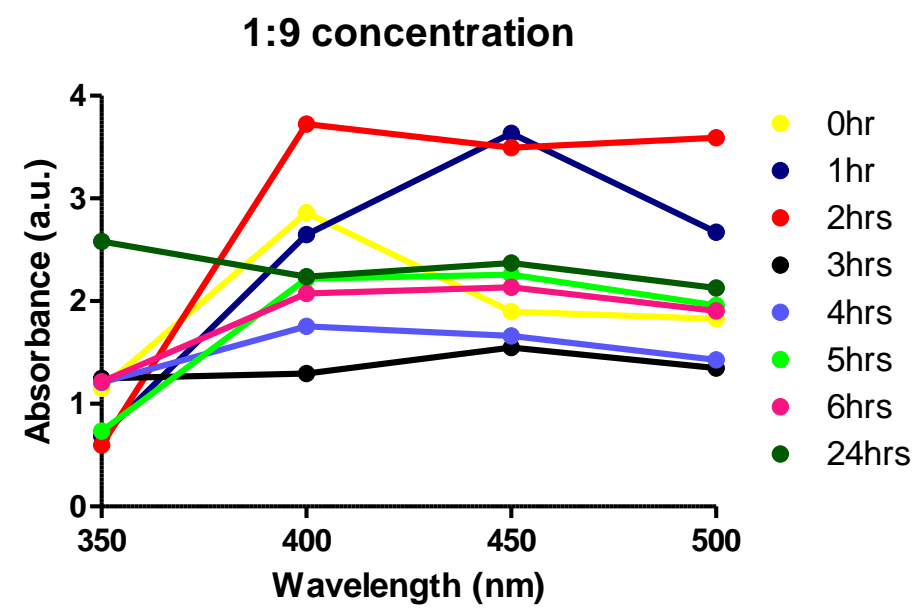

Figure 7. Effect of mixing ratio on the surface plasmon resonance of AgNPs with 1:9 mixing ratio.

The effect of temperature was continuously monitored for the optimal synthesis of silver nanoparticles for different mixing ration (Figure 8). The different absorbance pattern was noticed, but the maximum absorbance of 2.79 a.u. was obtained at $60{ }^{\circ} \mathrm{C}$ with $1: 8$ mixing ratio.

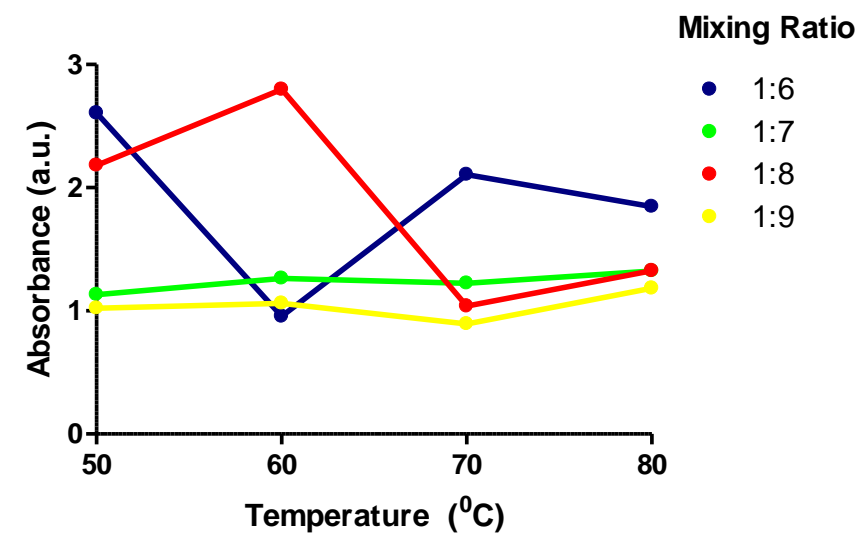

Figure 8. Effect of temperature on the surface plasmon resonance of AgNPs.

The effect of mixing concentration of salt and plant extract solution confirmed that at 1:8 mixing ratio, the maximum synthesis was achieved [17]. The rate of synthesis with respect 
to temperature was maximum at $60^{\circ} \mathrm{C}$ for Ag nanoparticles. The change in the absorbance with the reaction temperature and mixing ratio was also supported by Manikandan et al. (2020) [19].

\subsection{Physico-chemical characterization of silver nanoparticles.}

The biofunctionalized silver nanoparticles formed from the aqueous solution of $1 \mathrm{mM}$ $\mathrm{AgNO}_{3}$ with $5 \%$ aqueous leaves extract of Saraca indica at $60{ }^{0} \mathrm{C}$ temperature was characterized for particle size distribution. The peak number and peak amplitude obtained gave an important explanation for the size and size distribution of silver nanoparticles. The calculated particle size distribution by intensity was observed in the range of 10-100 nm (Figure 9). It can be seen that the mean particle size was $c a .49 .63 \mathrm{~nm}$, with some particles having diameters 100 to $1000 \mathrm{~nm}$. The polydispersity index (pdI) was 0.418.

Size Distribution by Intensity

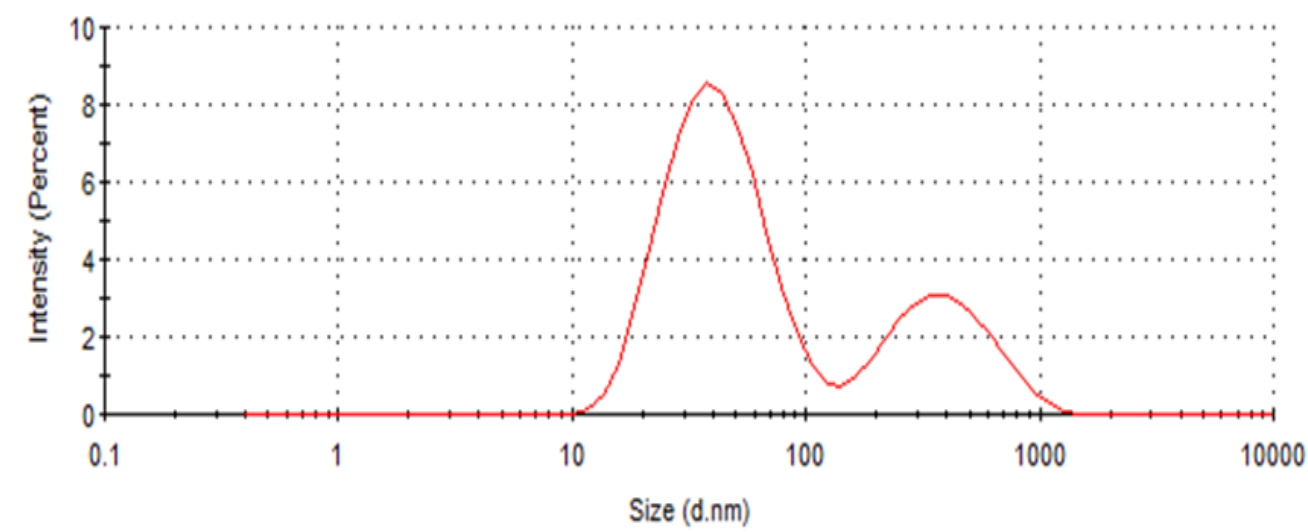

Figure 9. DLS size distribution of silver nanoparticles obtained from the reduction of $1 \mathrm{mM}$ silver nitrate at reaction temperatures, $60{ }^{\circ} \mathrm{C}$.

A mixture of a plate (spherical and hexagons) and spheres were obtained at $60{ }^{\circ} \mathrm{C}$ (Figure 10). Representative TEM images revealed the size distribution of AgNPs was in the range from 40 to $100 \mathrm{~nm}$. The high-resolution TEM displayed clear lattice fringes on the particle surfaces. The selected area electron diffraction pattern (SAED) of a single spherical particle confirmed the crystalline nature of AgNPs [13, 22].
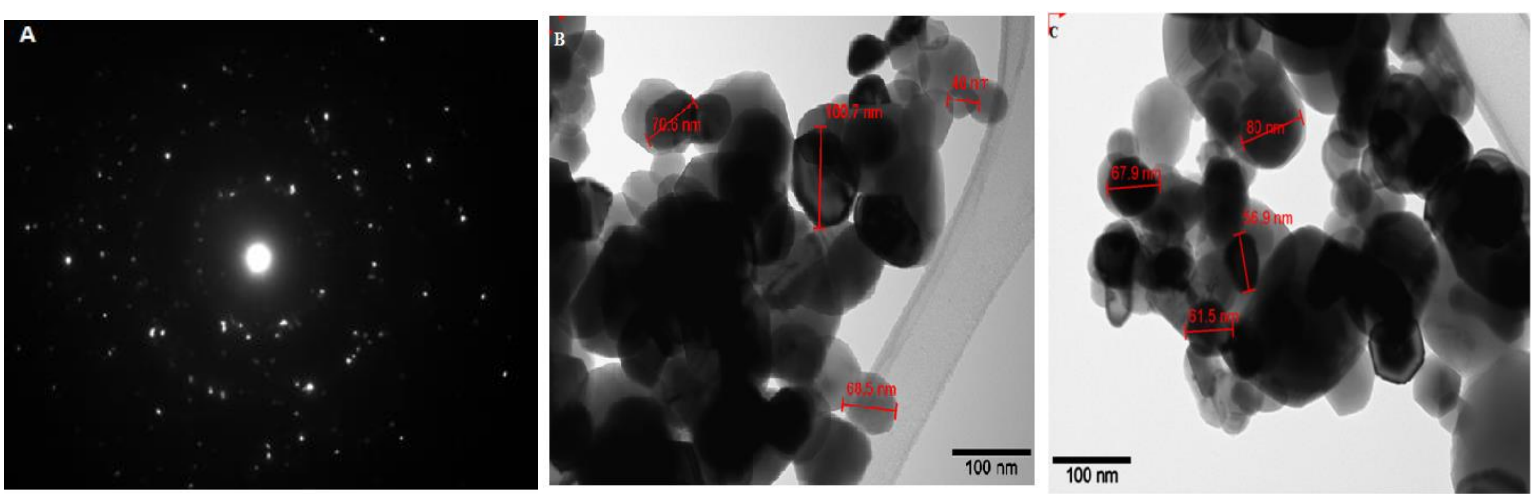

Figure 10. TEM micrographs recorded from a drop-coated film of a silver aqueous solution formed by the reaction of $1 \mathrm{mM} \mathrm{AgNO}_{3}$ and $5 \%$ Saraca indica leaf broth at reaction temperatures at $60{ }^{\circ} \mathrm{C}$. Selected area electron diffraction pattern (SAED) (A); Poly-disperse particle size (B-C).

FTIR analysis was used for the functional group characterization of the silver nanoparticles optimized at $60{ }^{\circ} \mathrm{C}$ (Figure 11). The absorbance bands were observed in the 
region of 500-4500 $\mathrm{cm}^{-1}$. The strong, intense peaks were seen at $3445 \mathrm{~cm}^{-1}, 2077 \mathrm{~cm}^{-1}$, and $1633 \mathrm{~cm}^{-1}$ respectively. The maximum intense peak of $3445 \mathrm{~cm}^{-1}$ corresponds to the stretching mode of vibration of the amine group. The intense peak $2077 \mathrm{~cm}^{-1}$ corresponds to the stretching mode of vibration of aldehydes and the intense peak at $1633 \mathrm{~cm}^{-1}$ correspond to carbonyl group, flavonoids, and steroids group. Singh et al., (2014) concluded that bio-organic like sterols, hydrocarbons, calcium compounds flavonoids, lignin glycosides, lyoniside, tannins, quercetin, alkaloids, alcohol, and beta-sitosterol of the leaves worked as the capping for nanoparticles [23]. These pigments have reductive properties and get released to solution by diffusion [24].

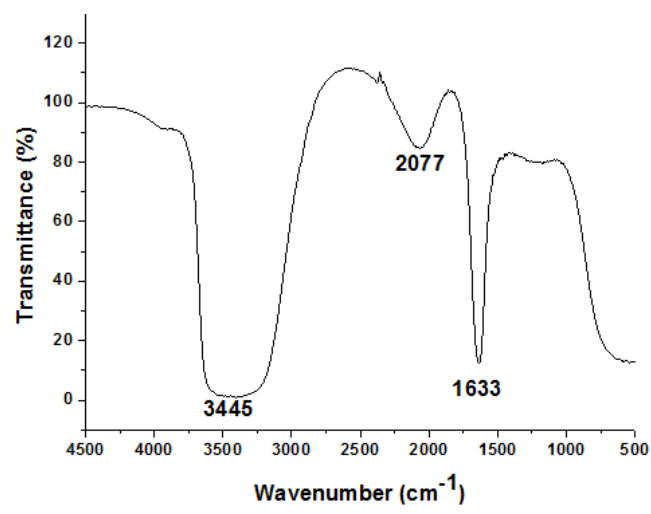

Figure 11. FTIR spectra of silver nanoparticles.

\subsection{Antimicrobial mechanism of nanoparticle and drug formulation.}

Next, we optimized testing conditions and evaluated the antibacterial susceptibility of rapid biologically synthesized S. indica silver nanoparticles and commercial drugs against Gram-negative (E. coli) and Gram-positive (S. aureus) bacteria. The zone of inhibition was evaluated by the disc diffusion method [25]. The surface chemistry and size pattern of metallic ions of the nanometer range helped us to investigate the efficacy of silver nanoparticles as a drug carrier. To understand the mechanisms, a comparative analysis of drugs formulated with nanoparticles was performed. The in-vitro antibacterial activity of ampicillin and ciprofloxacin, along with their nanoformulation, were tested against bacterial strains. The zone of inhibition for ciprofloxacin formulated silver nanoparticles for $E$. coli was more significant than ampicillin nanocolloids. Whereas, the zone of inhibition for both nanoformulation drugs against E. coli (amp 24 mm and cip 28 mm) and S. aureus $(\sim 18 \mathrm{~mm}$ and $\sim 16 \mathrm{~mm}$ )were highly significant than its pure form (Figure 12 and Figure 13).

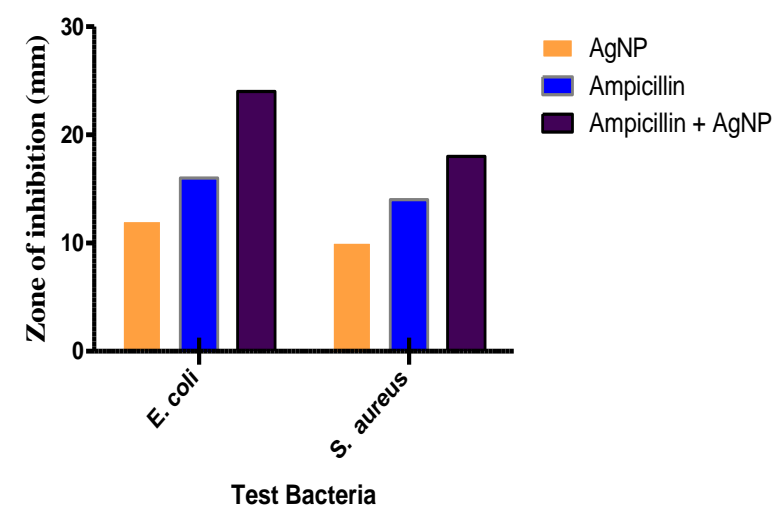

Figure 12. Graphical representation of the zone of inhibition for ampicillin drug mixed with AgNPs against the test bacteria. 


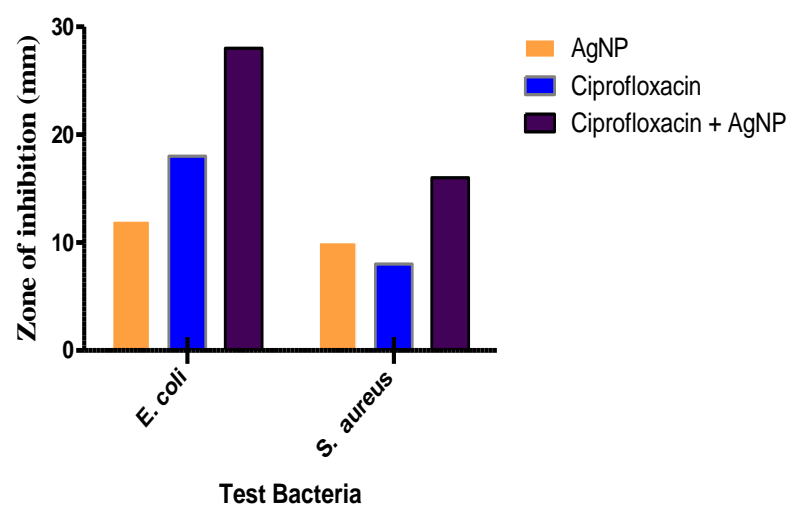

Figure 13. Graphical representation of the zone of inhibition for ciprofloxacin drug mixed with AgNPs against the test bacteria.

The underlying mechanism against the bacterial membrane has also been explained based on the nature of the material present in the cell wall. Thus, an easier permeability could be achieved in the case of gram-negative organisms [26]. Metal nanoparticle and drug formulations on attachment to the bacterial cells produces structural changes in the cell membrane, and block the transport channels [27-28]. The probable machinery approach of inhibition might be the loss in the ability to replicate genetic material and immobilization of certain cellular proteins and enzymes required for ATP synthesis [29-31].

\section{Conclusions}

It is predicted that nanotechnology will have a $\$ 3.1$ trillion impact on the global economy by 2020. The green synthesis of silver nanoparticles was achieved using leaf extract of Saraca indica. The present study involved the comparative analysis of bacterial inhibition through drug formulated silver nanoparticles against test bacteria. It was observed that silver nanoparticles were highly stable, uniformed in shape, and smaller in size. The physicochemical parameters helped in optimization for maximum synthesis. The findings create a new standard where the different carotenoids and alkaloids-functionalized metal nanoparticles might be used as a powerful weapon in the field of nanomedicine.

\section{Funding}

This research received no external funding.

\section{Acknowledgments}

Authors are also thankful to the Department of Biotechnology, M.M.D.U., Mullana.

\section{Conflicts of Interest}

The authors declare no conflict of interest.

\section{References}

1. Singh, M.; Kumar, M.; Kalaivani, R.; Manikandan, S.; Kumaraguru, A.K. Metallic silver nanoparticle: a therapeutic agent in combination with antifungal drug against human fungal pathogen. Bioprocess and Biosystems Engineering 2013, 36, 407-415, https://doi.org/10.1007/s00449-012-0797-y. 
2. Navya, P.N.; Daima, H.K. Rational engineering of physicochemical properties of nanomaterials for biomedical applications with nanotoxicological perspectives. Nano Convergence 2016, 3, https://doi.org/10.1186/s40580-016-0064-z.

3. Mousavi-Khattat, M.; Keyhanfar, M.; Razmjou, A. A comparative study of stability, antioxidant, DNA cleavage and antibacterial activities of green and chemically synthesized silver nanoparticles. Artificial Cells, Nanomedicine, and Biotechnology $2018, \quad 46, \quad$ S1022-S1031 ,https://doi.org/10.1080/21691401.2018.1527346.

4. Ribeiro, A.P.C.; Anbu, S.; Alegria, E.C.B.A.; Fernandes, A.R.; Baptista, P.V.; Mendes, R.; Matias, A.S.; Mendes, M.; Guedes da Silva, M.F.C.; Pombeiro, A.J.L. Evaluation of cell toxicity and DNA and protein binding of green synthesized silver nanoparticles. Biomedicine \& Pharmacotherapy 2018, 101, 137-144, https://doi.org/10.1016/j.biopha.2018.02.069.

5. Tiwari, G.; Tiwari, R.; Sriwastawa, B.; Bhati, L.; Pandey, S.; Pandey, P.; Bannerjee, S.K. Drug delivery systems: An updated review. International journal of pharmaceutical investigation 2012, 2, 2-11, https://doi.org/10.4103/2230-973x.96920.

6. Girilal, M.; Mohammed Fayaz, A.; Elumalai, L.K.; Sathiyaseelan, A.; Gandhiappan, J.; Kalaichelvan, P.T. Comparative Stress Physiology Analysis of Biologically and Chemically Synthesized Silver Nanoparticles on Solanum Lycopersicum L. Colloid and Interface Science Communications 2018, 24, 1-6, https://doi.org/10.1016/j.colcom.2018.02.005.

7. Chen, X.; Guo, Z.; Tang, Y.; Shen, Y.; Miao, P. A highly sensitive gold nanoparticle-based electrochemical aptasensor for theophylline detection. Analytica Chimica Acta 2018, 999, 54-59, https://doi.org/10.1016/j.aca.2017.10.039.

8. Ohara, Y.; Akazawa, K.; Shibata, K.; Hirota, T.; Kodama, Y.; Amemiya, T.; Wang, J.; Yamaguchi, T. Seedmediated gold nanoparticle synthesis via photochemical reaction of benzoquinone. Colloids and Surfaces A: Physicochemical and Engineering Aspects 2020, 586, https://doi.org/10.1016/j.colsurfa.2019.124209.

9. Ahmed, S.; Ahmad, M.; Swami, B.L.; Ikram, S. A review on plants extract mediated synthesis of silver nanoparticles for antimicrobial applications: A green expertise. Journal of Advanced Research 2016, 7, 17 28, https://doi.org/10.1016/j.jare.2015.02.007.

10. Singh, M.; Manikandan, S.; Yadav, M.; Kumar, S.; Sehrawat, N.; Meashi, V.; Diksha; Sharma, P.; Kumar, A. Bio-functionalized Gold Nanoparticles: A Potent Probe for Profound Antibacterial Efficiency through Drug Delivery System. Asian Journal of Biological Sciences 2020, 9, 42-47.

11. Chauhan, N.; Tyagi, A.K.; Kumar, P.; Malik, A. Antibacterial Potential of Jatropha curcas Synthesized Silver Nanoparticles against Food Borne Pathogens. 2016, 7, https://doi.org/10.3389/fmicb.2016.01748.

12. Buszewski, B.; Railean-Plugaru, V.; Pomastowski, P.; Rafińska, K.; Szultka-Mlynska, M.; Golinska, P.; Wypij, M.; Laskowski, D.; Dahm, H. Antimicrobial activity of biosilver nanoparticles produced by a novel Streptacidiphilus durhamensis strain. Journal of Microbiology, Immunology and Infection 2018, 51, 45-54, https://doi.org/10.1016/J.JMII.2016.03.002.

13. Tyagi, S.; Tyagi, P.K.; Gola, D.; Chauhan, N.; Bharti, R.K. Extracellular synthesis of silver nanoparticles using entomopathogenic fungus: Characterization and antibacterial potential. SN Applied Sciences 2019, 1, https://doi.org/10.1007/s42452-019-1593-y.

14. Hariram, M.; Vivekanandhan, S.; Ganesan, V.; Muthuramkumar, S.; Rodriguez-uribe, A.; Mohanty, A.K.; Misra, M. Tecoma stans flower extract assisted biogenic synthesis of functional Ag-Talc nanostructures for antimicrobial applications. Bioresource Technology Reports 2019, 7, https://doi.org/10.1016/J.BITEB.2019.100298.

15. Pugazhendhi, A.; Prabakar, D.; Jacob, J.M.; Karuppusamy, I.; Saratale, R.G. Synthesis and characterization of silver nanoparticles using Gelidium amansii and its antimicrobial property against various pathogenic bacteria. Microbial Pathogenesis 2018, 114, 41-45, https://doi.org/10.1016/j.micpath.2017.11.013.

16. Yan, X.; He, B.; Liu, L.; Qu, G.; Shi, J.; Hu, L.; Jiang, G. Antibacterial mechanism of silver nanoparticles in Pseudomonas aeruginosa: proteomics approach. Metallomics 2018, 10, 557-564, https://doi.org/10.1039/c7mt00328e.

17. Agarwal, H.; Menon, S.; Kumar, S.V.; Rajeskumar, S. Mechanistic study on antibacterial action of Zinc oxide nanoparticles synthesized using green route. Chemico-Biological Interactions2018, 286, 60-70, https://doi.org/10.1016/j.cbi.2018.03.008.

18. Kołodziej, B.; Kowalski, R. Antibacterial and antimutagenic activity of extracts aboveground parts of three Solidago species: Solidago virgaurea L., Solidago canadensis L. and Solidago gigantea Ait. Journal of Medicinal Plants Research 2011, 5.

19. Manikandan, S.; Sankarlal, S.; Singh, M.; Sharma, A.K.; Ganesapandian, S.; Kumaraguru, A.K. Padina gymnospora derived a linear polysaccharide "alginate" mediated synthesis of silver nanocomposite and its antibacterial activity. Letters in Applied NanoBioScience 2020, 9, 1136-1140.

20. Singh, M.; Chandrasekaran, N.; Mukherjee, A.; Kumar, M.; Kumaraguru, A.K. Cancerous cell targeting and destruction using $\mathrm{pH}$ stabilized amperometric bioconjugated gold nanoparticles from marine macroalgae, Padina gymnospora. Bioprocess and Biosystems Engineering 2014, 37, 1859-1869, https://doi.org/10.1007/s00449-014-1160-2. 
21. Singh, M.; Kalaivani, R.; Manikandan, S.; Sangeetha, N.; Kumaraguru, A.K. Facile green synthesis of variable metallic gold nanoparticle using Padina gymnospora, a brown marine macroalga. Applied Nanoscience 2012, 2, 1-7

22. Ji, X.; Song, X.; Li, J.; Bai, Y.; Yang, W.; Peng, X. Size control of Gold nanocrystals in citrate reduction: The third role of citrate. Journal of the American Chemical Society 2007, 129, 13939-13948, https://doi.org/10.1021/ja074447k.

23. Singh, M.; Kumar, M.; Manikandan, S.; Chandrasekaran, N.; Mukherjee, A.; Kumaraguru, A.K. Drug delivery system for controlled cancer therapy using physico-chemically stabilized bioconjugated gold nanoparticles synthesized from marine macroalgae, Padina gymnospora. Journal of Nanomedicine Nanotechology 2014, S5, https://doi.org/10.4172/2157-7439.S5-009.

24. Mariychuk, R.; Fejer, J.; Porubska, J.; Grishchenko, L.M.; Lisnyak, V.V. Green synthesis and characterization of gold triangular nanoprisms using extract of Juniperus communis L. Applied Nanoscience2 019, https://doi.org/10.1007/s13204-019-00990-X.

25. Shameli, K.; Ahmad, M.B.; Jazayeri, S.D.; Shabanzadeh, P.; Sangpour, P.; Jahangirian, H.; Gharayebi, Y. Investigation of antibacterial properties silver nanoparticles prepared via green method. Chemistry Central Journal 2012, 6, 1-10, https://doi.org/10.1186/1752-153X-6-73.

26. Shamaila, S.; Zafar, N.; Riaz, S.; Sharif, R.; Nazir, J.; Naseem, S. Gold Nanoparticles: An Efficient Antimicrobial Agent against Enteric Bacterial Human Pathogen. Nanomaterials 2016, 6, https://doi.org/10.3390/nano6040071.

27. Dutta, R.K.; Nenavathu, B.P.; Gangishetty, M.K.; Reddy, A.V.R. Studies on antibacterial activity of ZnO nanoparticles by ROS induced lipid peroxidation. Colloids and Surfaces B: Biointerfaces 2012, 94, 143150, https://doi.org/10.1016/j.colsurfb.2012.01.046.

28. Singh, M.; Renu.; Kamboj, S.; Kumari, S.; Kamboj, V.; Upadhyay, SK. One Pot Synthesis of Physicochemically Stabilized $\mathrm{ZnO}$ Nanoparticles via Biological Method and its Potential Application as Antimicrobial Agent. Bulletin of Pure and Applied Sciences 2020, 39A, 116-129. https://doi.org/10.5958/2320-3188.2020.00014.5.

29. Yamanaka, M.; Hara, K.; Kudo, J. Bactericidal Actions of a Silver Ion Solution on Escherichia coli, Studied by Energy-Filtering Transmission Electron Microscopy and Proteomic Analysis. Applied and Environmental Microbiology 2005, 71, 7589-7593,https://doi.org/10.1128/AEM.71.11.7589-7593.2005.

30. Durán, N.; Durán, M.; de Jesus, M.B.; Seabra, A.B.; Fávaro, W.J.; Nakazato, G. Silver nanoparticles: A new view on mechanistic aspects on antimicrobial activity. Nanomedicine: Nanotechnology, Biology and Medicine 2016, 12, 789-799,https://doi.org/10.1016/j.nano.2015.11.016.

31. Kumar, M.D.; Raji, P.; Bennet, R.D.; Gandham, R.G.; Sharma, V.K.; Keerthana, D.; Karishma, S.; Samrot, A.V.; Ponnaiah, P.; Thirumurugan, R.; Pattammadath, S.; Selvarani, J.; Prakash, P. Green Synthesis and antibacterial activity studies of silver nanoparticles from the aqueous extracts of Thespesia populnea. Letters in Applied NanoBioScience 2020, 9, 931 - 934, https://doi.org/10.33263/LIANBS91.931934. 